J. Lake Sci. (湖泊科学) , $2007, \mathbf{1 9}(3): 283-288$

http:// www. jlakes. org. E-mail: jlakes@ niglas. ac.cn

(C) 2007 by Journal of Lake Sciences

\title{
云南星云湖大街河口湖滨湿地修复及净化效果
}

\author{
李荫禾 ${ }^{1}$, 胡耀辉 ${ }^{2}$, 王云华 ${ }^{1}$, 祁云宽 ${ }^{1}$, 唐 芳 ${ }^{1}$, 刘 俊 ${ }^{1}$, 杨 林 $^{1}$ \\ (1:云南省玉溪市环境科学研究所,玉溪 653100) \\ (2:中国科学院南京地理与湖泊研究所,南京 210008)
}

摘 要: 星云湖人湖污染物负荷量 $80 \%$ 来自面源, 而河道是输送污染物的主要通道, 为了削减人湖污染物, 在大街河口未 端修复湖滨湿地 $4.5 \mathrm{hm}^{2}$, 恢复湖湾沉水植物 $28.8 \mathrm{hm}^{2}$, 对表流湿地及沉水植物的净化效果进行了试验研究. 研究结果表 明, 由于水生植物庞大的表面积吸附、分解和吸收作用、水质净化水质效果十分明显, 净化大街河水 $317.8 \times 10^{4} \mathrm{~m}^{3} / \mathrm{a}, \mathrm{SS}$ 、 $\mathrm{BOD}_{5} 、 \mathrm{COD}_{\mathrm{Mn}} 、 \mathrm{TN} 、 \mathrm{TP}$ 的去除率分别为 $82.8 \% 、 60.1 \% 、 52.8 \% 、 49.2 \% 、 40.7 \%$. 河口湖滨湿地的修复不仅净化了水质,而 且改善了河湾景观,恢复了湖泊生物多样性.

关键词:星云湖; 河口湿地;水质净化

\section{Wetland restoration and its purification efficiency in estuary of Dajie River, Lake Xingyun, Yunnan Province}

LI Yinxi ${ }^{1}$, HUYaohui ${ }^{2}$, WANG Yunhua ${ }^{1}$, QI Yunkuan ${ }^{1}$, TANG Fang ${ }^{1}$, LIU Jun ${ }^{1} \&$ YANG Lin $^{1}$ (1:Yuxi Institute of Environmental Science Research,Yuxi 653100,P. R. China)

(2:Nanjing Institute of Geography \& Limnology, Chinese Academy of Sciences, Nanjing 210008, P. R. China)

\begin{abstract}
About 80 percents of pollution of Lake Xingyun come from non-point sources, and rivers account primarily for transporting pollutants into Lake Xingyun. To reduce the pollutants, wetlands with an area of 4.5 ha was restored in estuarine areas of Dajie River. The total amount of purified river water was $317.810^{4} \mathrm{~m}^{3} / \mathrm{a}$. It was showed that the purification efficiency was significant via the combined mechanism of absorption, decomposition and assimilation of aquatic plants. The removal rates of $\mathrm{SS}, \mathrm{BOD}_{5}, \mathrm{COD}_{\mathrm{Mn}}, \mathrm{TN}$ and $\mathrm{TP}$ were $82.8 \%, 60.1 \%$, $52.8 \%, 49.2 \%$, and $40.7 \%$, respectively.
\end{abstract}

Keywords : Lake Xingyun; estuarine wetlands; purification efficiency for wastewater

湖滨湿地是湖泊自我保护屏障的自然生态系统, 由于围垦造田湖滨湿地已被破坏, 污染物直接入湖污 染水体. 利用湿地净化微污染水体已有报导 ${ }^{[1-4]}$, 但直接在河口修复湿地处理污染型河水并不多见, 本项 试验研究通过退耕围层农田人工修复河口湖滨湿地, 将人湖河水导流进人湿地系统净化后人湖, 并分别测 试了各系统间的净化效果, 以及河口湖滨湿地净化面源污染, 减少河水人湖污染物负荷量功能, 为利用生物 处理、净化人湖水质,改善河口、湖湾生态景观提供实用技术.

\section{1 大街河口区域生态系统变迁}

大街河川流于江川县城, 径流面积 $12.7 \mathrm{~km}^{2}$, 平均流量 $0.87 \times 10^{4} \mathrm{~m}^{3} / \mathrm{d}$, 人湖水量 $317.9 \times 10^{4} \mathrm{~m}^{3} / \mathrm{a}$. 河 口由于历史变迁沉积,形成三角洲浅水湖滩. 20 世纪 50 年代该湖湾生长大片芦苇及其它水生植物,湖滨湿 地很健全,物种十分丰富, 河水经漫流湿地后人湖, 河口区域自然生态系统良好, 对保护星云湖水质构筑了 自然的保护屏障. 20 世纪 70 年代初该湖湾被围湖造田, 湖滨湿地被破坏, 自然保护体系功能丧失, 湖滨湿 地变成农田后, 化肥农药流失直接入湖. 多年来随着径流区人口增加,农田化肥施用量逐年增多,生活污 
水、农田泄水汇人河流直接人湖, 人湖河水水质远超 V 类, 主要污染因子 TN 超 5 倍、TP 超 3 倍, 大街河湾污 染十分严重, 对星云湖水质污染负荷贡献率大. 由于人湖污染物逐年积累, 星云湖水质发生了质的变化, 2001 年由 III类下降为 IV 类,2002 年下降为 V 类,2004 年下降为劣 V 类,每年 3-10 月全湖蓝藻爆发, 星云湖 生态系统处于恶性循环.

\section{2 大街河湾湖滨湿地重建}

\section{1 大街河湾湖滨湿地建设工艺设计}

为了经济有效的消减人湖污染物,改善星云湖水质、课题组受玉溪市环保局委托开展大街河湾湖滨湿 地修复及净化试验示范研究.

工程因地制宜利用大街河人湖前比较宽的主河道建设沉淀坑, 以沉淀去除河水中的泥沙和悬浮杂物; 在河口处建设拦污网, 以拦截去除河水中的漂浮杂物; 将河湾 $4.5 \mathrm{hm}^{2}$ 农田退耕修复湖滨湿地, 并建设三道 导流埂布水; 在湖湾内浅水区恢复挺水植物、浮叶植物、飘浮植物和沉水植物 $15 \mathrm{hm}^{2}$, 对人湖河水进行深度 净化,全程大断面自流. 工艺流程见图 1. 工程 2001 年 12 月动工, 2002 年 5 月建成运行,设计处理能力 $8000 \mathrm{~m}^{3} / \mathrm{d}$.

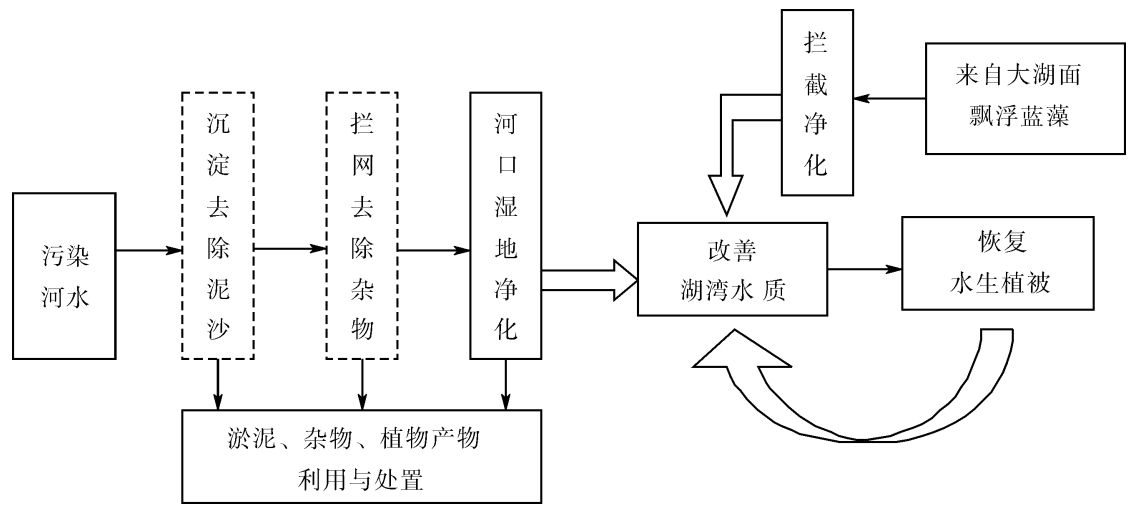

图 1 星云湖大街河湾生物净化工艺流程图

Fig. 1 Technological flow chart of biopurification project in estuary of Dajie River, Lake Xingyun

\section{2 河口湖滨湿地修复试验布局及种群配置}

根据河口自然地形及高程布设三级表流湿地,保证河水自然漫流深度 $0.1-0.7 \mathrm{~m}$, 主要种植当地挺水 植物:香蒲 (Typha latifolia)、艾草(Zizania cedu)、荷花 (Nelumbo nucifera)、芦苇 (Phragmites communis), 浅水 区域 $0.8-1.5 \mathrm{~m}$ 种植浮叶植物菱角 ( T. japonnica) 和飘浮植物凤眼莲 (Eichhomia crassipes), 试验区具体布设 见图 2 ,种植规模及品种见表 1 .

表 1 试验区规模及种群布置

Tab. 1 Experimental area scope and species disposal

\begin{tabular}{ccccc}
\hline 试验单元 & 面积 $\left(\mathrm{m}^{2}\right)$ & 水深 $(\mathrm{m})$ & 种植品种 & 植物覆盖率 $(\%)$ \\
\hline 沉淀池 & 2500 & $2.5-3.0$ & - & - \\
一级表流湿地 & 9000 & $0.2-0.3$ & 香蒲、菱草 & 95 \\
二级表流湿地 & 11000 & $0.3-0.5$ & 艾草、香蒲 & 90 \\
三级表流湿地 & 25000 & $0.5-0.7$ & 荷花 & 90 \\
浮叶植物区 & 65000 & $0.8-1.5$ & 菱角、水葫芦 & 95 \\
沉水植物区 & 8500 & $02.0-3.5$ & 自然恢复红线草、菰尾藻 & $30-50$ \\
\hline
\end{tabular}




\section{3 试验监测点设置及方法}

根据各试验单元功能布设 6 个监测点位 (图 2). 监测时间 2003 年 5 月 - 2004 年 4 月,监测频率每月一

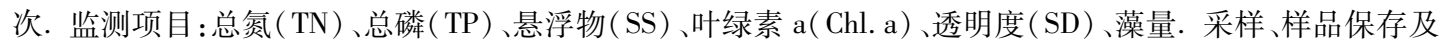
样品分析方法, 按照《水和废水监测分析方法》 (第四版) ${ }^{[5]}$ 分析, 生物部分按照 《环境监测技术规范》 ${ }^{[6]}$ 进 行分析.

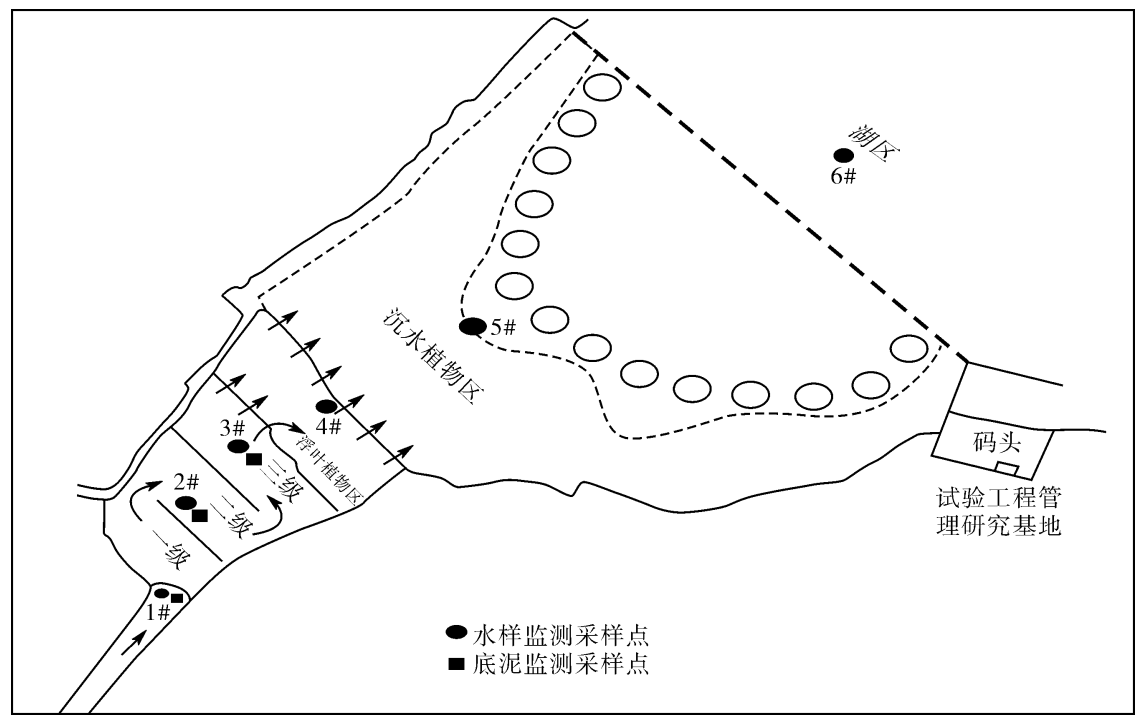

图 2 星云湖大街河湾生物净化工程监测点位置图

Fig. 2 Monitoring sites of biopurification project in estuary of Dajie River, Xingyun Lake

\section{3 结果与分析}

\section{1 试验区水质净化效果}

试验区水生植物长势茂盛,湖湾湖滨湿地恢复良好,经过一整年的采样测试分析结果表明,河口湖滨湿 地系统对人湖河水水质净化效果十分显著, $\mathrm{SS}$ 的去除率达 $83.2 \%$ 、 TN 的去除率达 $49.2 \%$ 、TP 的去除率达 $52.3 \% 、 \mathrm{COD}_{\mathrm{Mn}}$ 的去除率达 $52.8 \% 、 \mathrm{BOD}_{5}$ 的去除率达 $60.2 \%$ (表 2). 人湖河水漫流进人表流湿地,经过土壤 及水生植物庞大表面积上微生物的分解、吸收, 河水中的污染物得到降解, 有效的削减人湖污染物, 改善了 湖湾的水质及生态环境.

表 2 星云湖大街河口湖滨湿地系统净化效果

Tab. 2 Purification efficiency of estuarine wetland system in Dajie River, Xingyun Lake

\begin{tabular}{|c|c|c|c|c|c|c|c|}
\hline 采样点 & $\begin{array}{l}1^{\#} \text { 大街 } \\
\text { 河人口 }\end{array}$ & $\begin{array}{c}2^{\#} \text { 一级湿地 } \\
\text { 出口 }\end{array}$ & $\begin{array}{c}3^{\# \text { 二级湿 }} \\
\text { 地出口 }\end{array}$ & $\begin{array}{c}4^{\#} \text { 三级湿 } \\
\text { 地出口 }\end{array}$ & $\begin{array}{c}5^{\#} \text { 沉水植 } \\
\text { 物区 }\end{array}$ & $\begin{array}{l}6^{\#} \text { 试验 } \\
\text { 外湖区 }\end{array}$ & $\begin{array}{c}\text { 总去除率 } \\
(\%)\end{array}$ \\
\hline $\mathrm{SS}(\mathrm{mg} / \mathrm{L})$ & 107 & 55 & 28 & 20 & 18 & 23 & 83.2 \\
\hline $\mathrm{TN}(\mathrm{mg} / \mathrm{L})$ & 10.672 & 7.670 & 6.591 & 6.175 & 5.425 & 2.279 & 49.2 \\
\hline $\mathrm{TP}(\mathrm{mg} / \mathrm{L})$ & 1.177 & 0.870 & 0.769 & 0.648 & 0.562 & 0.425 & 52.3 \\
\hline $\mathrm{COD}_{\mathrm{Mn}}(\mathrm{mg} / \mathrm{L})$ & 18.64 & 13.79 & 12.49 & 10.53 & 8.80 & 7.92 & 52.8 \\
\hline $\mathrm{BOD}_{5}(\mathrm{mg} / \mathrm{L})$ & 13.05 & 8.65 & 5.66 & 5.44 & 5.20 & 4.69 & 60.2 \\
\hline
\end{tabular}

\section{2 各单元水生植物水质净化效果分析}

根据全年监测分析数据, 统计出各系统削减污染物去除率 (表 3 , 图 3 ), 可以看出, 表流湿地中艾草 + 香 蒲群落的净化效果最佳. 荠草、香蒲表流湿地的水力负荷为 $0.4 \mathrm{~m}^{3} /\left(\mathrm{m}^{2} \cdot \mathrm{d}\right)$, 滞留时间为 $18 \mathrm{~h}$. 由于人湖 
河水各种污染物浓度很高, 为植物的生长提供了物质条件, 植物生长十分茂盛, 密度 $53-76$ 株/ $\mathrm{m}^{2}$, 生物量 达 $25-50 \mathrm{~kg} / \mathrm{m}^{2}$. 植物茂密的茎杆构成了层层叠叠的生物滤网, 植物茎杆表面形成了生物膜 ${ }^{[2]}$, 微生物的 同化作用及植物的吸收、降解、拦截沉淀等复合作用,净化了河水中的各种污染物,去除率 SS 达 $48.6 \% 、 \mathrm{TN}$ 达 $28.1 \%$ 、 $\mathrm{TP}$ 达 $26.1 \% 、 \mathrm{COD}_{\mathrm{MN}}$ 达 $26.0 \% 、 \mathrm{BOD}_{5}$ 达 $33.7 \%$. 在一、级表流湿地中去除的污染物约占总去 除量的 $50 \%$.

第三级荷花湿地的水力负荷为 $0.32 \mathrm{~m}^{3} /\left(\mathrm{m}^{2} \cdot \mathrm{d}\right)$, 滞留时间为 $30 \mathrm{~h}$,植株密度 $6-11$ 株 $/ \mathrm{m}^{2}$, 生物量 5.4 $-6.2 \mathrm{~kg} / \mathrm{m}^{2}$. 虽然荷花湿地的水力负荷小, 滞留时间长, 但与香蒲和荠草相比净化效果要差一些, 去除率 $\mathrm{SS}$ 达 $25.2 \%$, TN 达 $10.0 \% 、 \mathrm{COD}_{\mathrm{Mn}}$ 达 $7.0 \% 、 \mathrm{BOD}_{5}$ 达 $22.9 \%$.

菱角、水葫芦种植于湖湾浅水区, 植物的覆盖率达 $90 \%-100 \%$, 植株密度 $80-120$ 株 $/ \mathrm{m}^{2}$, 生物量 $40-$ $50 \mathrm{~kg} / \mathrm{m}^{2}$. 该试验区对 TN 的去除率低, 这是由于植物体覆盖整个水面, 底层水体中溶解氧较少, 该区域底 层水体处于厌氧状态, 促使反硝化作用较强, 而硝化作用较弱的原因所致 ${ }^{[4]}$, 但对 $\mathrm{TP} 、 \mathrm{COD}_{\mathrm{Mn}}$ 的净化效果较 明显分别为 $10.3 \% 、 10.5 \%$ (图 3).

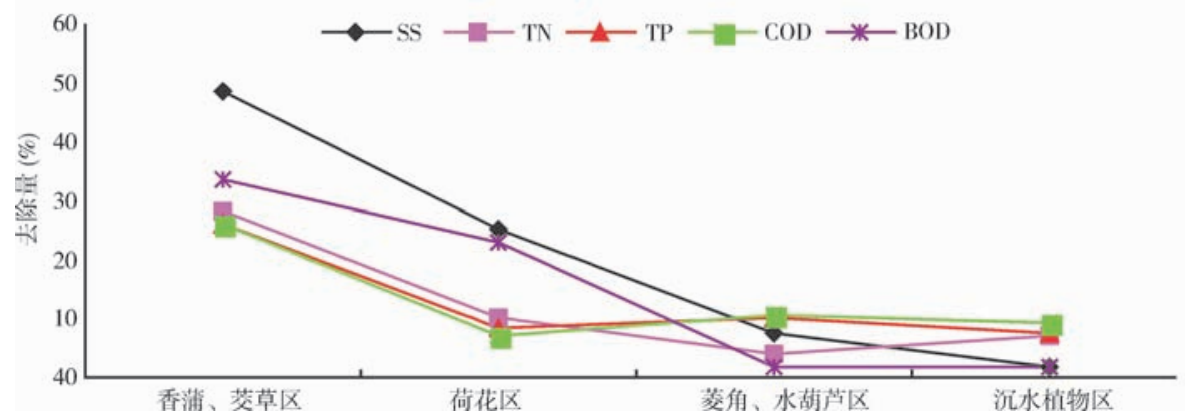

图 3 星云湖大街河湾生物净化工程各处理系统去除率

Fig. 3 Removal rates of disposal systems of biopurification project in estuary of Dajie River, Lake Xingyun

\section{3 河口湿地污染物滞留率分析}

各个处理系统的净化效果与生物量直接有关,生物量越大, 吸收的污染物质越多,水体净化的作用就越 强 (表 4). 试验区植物净化能力的排序是: 荠草 > 香蒲 > 荷花. 荠草的再生能力很强,一年可以收割 4 次, 是牛、马的青饲料, 茎叶可资源化综合利用, 可减少植物残体造成的二次污染, 荠草是湖滨湿地首选物种. 荷花虽然净化效果相对弱一些,但营造的生态景观十分美丽,把它种植在水质浓度低的区域较为理想.

表 4 河口湖滨湿地生物量及污染物滞留量

Tab. 4 Biomass and pollutant retention time in estuarine wetland of Dajie River

\begin{tabular}{|c|c|c|c|c|c|c|}
\hline \multirow{2}{*}{ 植物名称 } & \multirow{2}{*}{$\begin{array}{c}\text { 种植面积 } \\
\left(\mathrm{m}^{2}\right)\end{array}$} & \multirow{2}{*}{$\begin{array}{l}\text { 年生长量 } \\
\left(\mathrm{kg} / \mathrm{m}^{2}\right)\end{array}$} & \multirow{2}{*}{$\begin{array}{l}\text { 含水率 } \\
(\%)\end{array}$} & \multicolumn{3}{|c|}{ 植物体干物质含量 $(\%)$} \\
\hline & & & & $\mathrm{TN}$ & $\mathrm{TP}$ & 有机质 \\
\hline 香蒲 & 2500 & 25.7 & 81.9 & 0.804 & 0.207 & 59.95 \\
\hline 艾草 & 17500 & 32,0 & 81.2 & 0,717 & 0.178 & 65.63 \\
\hline 荷花 & 25000 & 7,20 & 90.0 & 0,621 & 0.214 & 57.00 \\
\hline 菱角 & 45000 & 15,0 & 91.6 & 2,207 & 0.546 & 41.20 \\
\hline 水葫芦 & 20000 & 25.0 & 94.3 & 1,040 & 0.491 & 36.35 \\
\hline
\end{tabular}

\section{4 河口湖滨湿地削减入湖污染总量分析}

大街河生物净化试验工程运行去除污染负荷总量包括湿地自身水质净化去除量、水生植物收割移出 量、生物促进污水中 SS 沉积效应清除淤泥移出量、拦污网拦截打捞垃圾杂物移出量. 经过 $2003-2004$ 年对 湿地水质的跟踪监测及 2003 年 11 月、2004 年 8 月两次对湿地生物量、淤泥量的调查和采样分析, 整个试 
验区年去除氮、磷污染负荷总量分别为 $24.5 \mathrm{t}$ 和 $5.811 \mathrm{t}$, 去除有机质 $287.926 \mathrm{t}$ (表 5 ).

表 5 大街河口湖滨湿地试验区人湖污染负荷总削减量

Tab. 5 Total removal amount of influent pollution in experimental area of estuarine wetland of Dajie River

\begin{tabular}{cccccc}
\hline 类别 & $\begin{array}{c}\text { 产生量 } \\
(\mathrm{t} \text {,湿重 })\end{array}$ & $\begin{array}{c}\text { 产生量 } \\
(\mathrm{t} \text {,干重 })\end{array}$ & $\begin{array}{c}\mathrm{TN} \text { 去除量 } \\
(\mathrm{t})\end{array}$ & $\begin{array}{c}\mathrm{TP} \text { 去除量 } \\
(\mathrm{t})\end{array}$ & $\begin{array}{c}\text { 有机质去除量 } \\
(\mathrm{t})\end{array}$ \\
\hline 湿地自身净化对污染物去除 & & & 17.084 & 1.369 & \\
植物收割去除消减污染物 & 2843.48 & 335.04 & 3.855 & 1.137 & 184.64 \\
泥沙去除消减污染物 & 9206.02 & 2642.13 & 4.137 & 3.219 & 100.566 \\
垃圾打捞消减污染物 & 474.5 & 95.36 & 0.38 & 0.086 & 2.72 \\
合 计 & 12526.3 & 3072.53 & 25.456 & 5.811 & 287.926 \\
\hline
\end{tabular}

\section{5 河口湖滨湿地对沉水植物恢复的影响分析}

大街河水经过三角洲表流湿地拦截净化后, $80 \%$ 以上的悬浮物被降解吸附,湖湾水体透明度从 $0.60 \mathrm{~m}$ 上升到 $1.55 \mathrm{~m}$, 随着透明度的上升, 为沉水植物的恢复创造了条件,沉水植物由浅水区向深水区渐渐自然恢 复, 恢复的规律是耐污种类先出现, 随着水质的改善, 清水性物种渐渐出现, 即次序是: 红线草 (Patamogeton Pectinatus)、狐尾藻 (Myriophyllum Linn)、淔草 (Patamogeton Crispus L. )、黑藻 (Hydrilla Verticillata ( L. f.) Royle. )、水鳖 (Hyodrocharis dubia (Bl. ) Backer. )、苦草(Vallisneria spiralis L). 沉水植物的恢复增大了水体 净化的表面积, 提高水质深度净化效果, 同时沉水植物的恢复可有效的控制蓝藻的生长. $2003-2004$ 年对 菱角、水葫芦区、沉水植物区进行调查,试验外湖泊区为对照点,结果见表 6 .

试验区各项参数都比湖区低, 沉水植物区的透明度比湖区提高 $72 \%$ 、蓝藻生物量降低 $51.7 \%$ 、叶绿素 a 下降 $21 \%$,菱角、水葫芦区蓝藻生物量比湖区降低 $73.4 \%$ 、叶绿素 a 降低 $43.1 \%$. 表明浮叶植物、沉水植物 对控制蓝藻确实是有效的. 对于蓝藻暴发频繁的星云湖,恢复沉水植物是控制蓝藻的途径之一.

表 6 试验区透明度、蓝藻和叶绿素 a 测值

Tab. 6 Monitoring results of transparence, wikipedia and chlorophyll a in experimental area

\begin{tabular}{cccc}
\hline \multirow{2}{*}{ 项 $\quad$ 目 } & \multicolumn{3}{c}{ 监测点位 } \\
\cline { 2 - 4 } & 菱角、水葫芦区 $\left(4^{\#}\right)$ & 沉水植物区 $\left(5^{\#}\right)$ & 湖泊区 $\left(6^{\#}\right)$ \\
\hline 水生植物覆盖度 $(\%)$ & 80 & $80($ 浅水 $)-50($ 深水 $)$ & 无 \\
透明度 $(\mathrm{cm})$ 平均值 & $80($ 水深 $1 \mathrm{~m})$ & $155($ 水深 $2-3 \mathrm{~m})$ & $90($ 水深 $4-5 \mathrm{~m})$ \\
蓝藻 $\left(\times 10^{4} \mathrm{cell} / \mathrm{s} / \mathrm{L}\right)$ 平均值 & 309.4 & 562.7 & 1164.6 \\
叶绿素 $\mathrm{a}\left(\mathrm{mg} / \mathrm{m}^{3}\right)$ 平均值 & 39.93 & 55.50 & 70.19 \\
\hline
\end{tabular}

\section{4 结论与建议}

星云湖大街河口湖滨湿地系统修复有效削减了人湖污染负荷量,总去除率 SS 达 $83.2 \%$ 、TN 达 $49.2 \%$ 、 $\mathrm{TP}$ 达 $52.3 \% 、 \mathrm{COD}_{\mathrm{Mn}}$ 达 $52.8 \% 、 \mathrm{BOD}_{5}$ 达 $60.1 \%$; 试验区艾草、香蒲群落的净化效果最佳, 并且茎、叶可资源 化综合利用, 是修复湖滨湿地的首选物种; 河口湖滨湿地的修复为湖湾沉水植物的恢复创造了条件, 透明度 提高了 $72 \%$, 沉水植物自然恢复面积 $85000 \mathrm{~m}^{2}$, 覆盖率达 $50 \%-80 \%$, 沉水植物控制蓝藻繁殖, 蓝藻生物量 比湖区降低 $51.7 \%$.

试验表明,河口湖滨湿地的修复是控制面源污染的措施之一,投资低,效果明显,易管理,不仅净化了水 质, 而且改善了湖湾生态境观, 对修复湖泊完整的生态系统起到积极的作用, 增强了湖泊的活力. 该试验已 经验收,并已在同湖的其它三条河口推广实施运用.

(1) 湖泊富营养化的原因都是由于水流载体中营养物质的增多而引起湖体中营养物质浓度升高, 导致 
蓝藻爆发, 因此控制陆源人湖是遏制湖泊富营养的关键.

(2) 由于河水流量受季节的影响,暴雨期间水量过大, 河口湿地负荷过重,滞留时间短,水质净化效果 差, 如果要提高净化能力, 要占用大量的土地, 所以只要将每场雨水的头 $1 \mathrm{~h}$ 的雨水截人湿地净化, 因首场 雨水冲刷地表污物汇集的水质污染浓度高于后面的 5-10 倍,对湖泊水质的影响最大.

(3) 星云湖 12 条河流入湖水量 $3831 \times 10^{4} \mathrm{~m}^{3} / \mathrm{a}$, 占总地表径流的 $67 \%$, 经河流输送的营养物质占湖盆 区陆源总量的 $80 \%$. 可见修复河口湖滨湿地是河口未端污染治理最经济、有效的生物治理措施. 可分别在 其余的河口湖湾因地制宜实施,构筑一条湖泊生态系统自我保护屏障的体系.

(4) 管理是确保湖滨湿地正常稳定运行的关键, 因此一定加强管理, 并定时收割植物及清除沉淀池的 淤泥,避免植物残体造成二次污染.

\section{5 参考文献}

[1] 吴振斌,周巧红, 贺 锋等. 构建湿地中试系统基质剖面微生物活性的研究. 中国环境科学, 2003,23 (4).

［2］汪俊三. 华南地区 11 种高等水生维管束植物净化城镇污水效益评价. 农村生态环境学报, 1995,11 (1).

[3] 豆俊锋,罗固源,刘 翔. 生物除磷过程厌氧释磷的代谢机理及其动力学分析. 环境科学学报,2005,25 (9).

[4] 陈源高, 李文朝,李荫胥等. 云南抚仙湖窑泥沟复合湿地的除氮效果. 湖泊科学, 2004,16(4):331 -336 .

５］国家环境保护总局. 水和废水监测分析方法.第 4 版. 北京:中国环境科学出版社,2002.

６］国家环保局. 环境监测技术规范 (第四册): 生物监测 (水环境) 部分. 北京: 中国环境科学出版 社, 1986. 